\title{
Climate change impacts on extreme temperature mortality in select metropolitan areas in the United States
}

\author{
David Mills • Joel Schwartz • Mihye Lee • \\ Marcus Sarofim • Russell Jones • Megan Lawson • \\ Michael Duckworth • Leland Deck
}

Received: 31 January 2013 /Accepted: 22 May 2014 / Published online: 13 June 2014

(C) The Author(s) 2014. This article is published with open access at Springerlink.com

\begin{abstract}
This paper applies city-specific mortality relationships for extremely hot and cold temperatures for 33 Metropolitan Statistical Areas in the United States to develop mortality projections for historical and potential future climates. These projections, which cover roughly 100 million of 310 million U.S. residents in 2010, highlight a potential change in health risks from uncontrolled climate change and the potential benefits of a greenhouse gas (GHG) mitigation policy. Our analysis reveals that projected mortality from extremely hot and cold days combined increases significantly over the 21 st century because of the overwhelming increase in extremely hot days. We also find that the evaluated GHG mitigation policy could substantially reduce this risk. These results become more pronounced when accounting for projected population changes. These results challenge arguments that there could be a mortality benefit attributable to changes in extreme temperatures from future warming. This
\end{abstract}

This article is part of a Special Issue on "A Multi-Model Framework to Achieve Consistent Evaluation of Climate Change Impacts in the United States” edited by Jeremy Martinich, John Reilly, Stephanie Waldhoff, Marcus Sarofim, and James McFarland.

Electronic supplementary material The online version of this article (doi:10.1007/s10584-014-1154-8) contains supplementary material, which is available to authorized users.

D. Mills $(\bowtie) \cdot$ R. Jones $\cdot$ M. Duckworth

Stratus Consulting Inc., 1881 Ninth Street, Suite 201, Boulder, CO 80302, USA

e-mail: dmills@stratusconsulting.com

J. Schwartz $\cdot$ M. Lee

Harvard School of Public Health, Department of Environmental Health, Department of Epidemiology,

Harvard University, 677 Huntington Avenue, Boston, MA 02115, USA

M. Sarofim

Climate Change Division (6207-J), U.S. Environmental Protection Agency, 1200 Pennsylvania Avenue NW, Washington, DC 20460, USA

M. Lawson

Headwaters Economics, P.O. Box 7059, Bozeman, MT 59771, USA

L. Deck

Clean Air Markets Division, U.S. Environmental Protection Agency, 1310 L Street, NW, Washington, DC 20005, USA 
finding of a net increase in mortality also holds in an analog city sensitivity analysis that incorporates a strong adaptation assumption. While our results do not address all sources of uncertainty, their scale and scope highlight one component of the potential health risks of unmitigated climate change impacts on extreme temperatures and draw attention to the need to continue to refine analytical tools and methods for this type of analysis.

\section{Introduction}

Climate change assessments consistently project increases in extremely hot days and decreases in extremely cold days (Karl et al. 2009; Meehl et al. 2009; IPCC 2011). The public health risks of extreme temperature days have long been recognized and, tragically, repeatedly demonstrated. As such, the future risk of climate-driven changes in the number and intensity of these days has been a topic of focused research for more than a decade (e.g., Kalkstein and Greene 1997; McGeehin and Mirabelli 2001; Basu and Samet 2002; Medina-Ramon and Schwartz 2007; Kinney et al. 2008; Anderson and Bell 2009, 2011; Huang et al. 2011; Sheridan et al. 2012; Zanobetti et al. 2012).

Quantitative results from this research are difficult to compare. Differences in extreme temperature definitions, analytical methods, time periods, affected populations, climate projections, and adaptation assumptions, among other items, underlie this difficulty. Despite these differences, these forward-looking studies have generally concluded that climate change will increase the health risks and mortality impacts associated with extreme temperatures in future climates.

This study's goal is to expand this earlier work. Specifically, we apply peer-reviewed, cityspecific extreme temperature-mortality relationships to project the mortality risk from changes in the number of future extremely hot and cold days. A focus of this analysis is to examine the net impact of climate change considering the combined impact on mortality from extremely hot and extremely cold days. Because we evaluate scenarios with and without greenhouse gas (GHG) emissions controls, we are able to quantify the potential benefits of such controls. Similarly, we evaluate scenarios with and without site-specific projected population changes. Finally, we evaluate one potential future extreme temperature adaptation assumption with an analog city approach.

\section{Data and methods}

\subsection{Daily mortality response to extreme temperatures}

We incorporate the criteria for extremely hot and cold days and the city-specific mortality results from Medina-Ramon and Schwartz (2007). Specifically, Medina-Ramon and Schwartz (2007) calculated the daily mortality impact for combinations of extremely cold and hot days in 50 cities using local mortality and weather data from 1989 to $2000 .{ }^{1}$ In their study, extreme temperature days were identified using the following criteria:

- Extremely hot day: a day from May to September with a daily minimum temperature greater than or equal to the 99th percentile value from that location's distribution and where this threshold value is greater than $20^{\circ} \mathrm{C}\left(68^{\circ} \mathrm{F}\right)$.

\footnotetext{
${ }^{1}$ Medina-Ramon and Schwartz (2007) use mortality data from all the counties in the Metropolitan Statistical Area for cities. For consistency, we use the populations of these areas to define our city results.
} 
- Extremely cold day: a day from November to March with a daily maximum temperature less than or equal to the 1 st percentile value from that location's distribution and where this threshold value is less than $10{ }^{\circ} \mathrm{C}\left(50^{\circ} \mathrm{F}\right)$.

To address the net mortality impact of projected changes in extreme temperature days, we restricted consideration to only cities with results for both extremely hot and cold days. Online Resource 1 presents the 33 cities from the Medina-Ramon and Schwartz (2007) evaluation that satisfied this criterion. Figure 1 presents the threshold temperatures and the associated percentage increase in daily mortality for each of these 33 cities for extremely hot and cold days respectively.

Using this city-specific information, we calculated deaths attributable to extremely hot temperatures within the city during a projected hot season using Eq. 1. Then we calculated deaths attributable to extremely cold temperatures using Eq. 1. Total mortality was calculated as the sum of deaths from hot and cold temperatures:

\section{Extreme temperature mortality = percentage change in daily mortality for an extreme temperature day $\times$} average deaths per day for the city $\times$ number of extreme temperature days in season

We used the Benefits Mapping and Analysis Program (BenMAP; U.S. EPA 2012) to develop estimates of the annual all-age mortality rate in the study cities. Use of the annual mortality rate was selected for consistency with the original study and then converted to a daily equivalent.

\subsection{Climate model and emissions scenarios}

Detailed descriptions of the emissions scenarios used in this analysis, along with a comparison to other emission scenarios (e.g., the Representative Concentration Pathways or RCPs) and

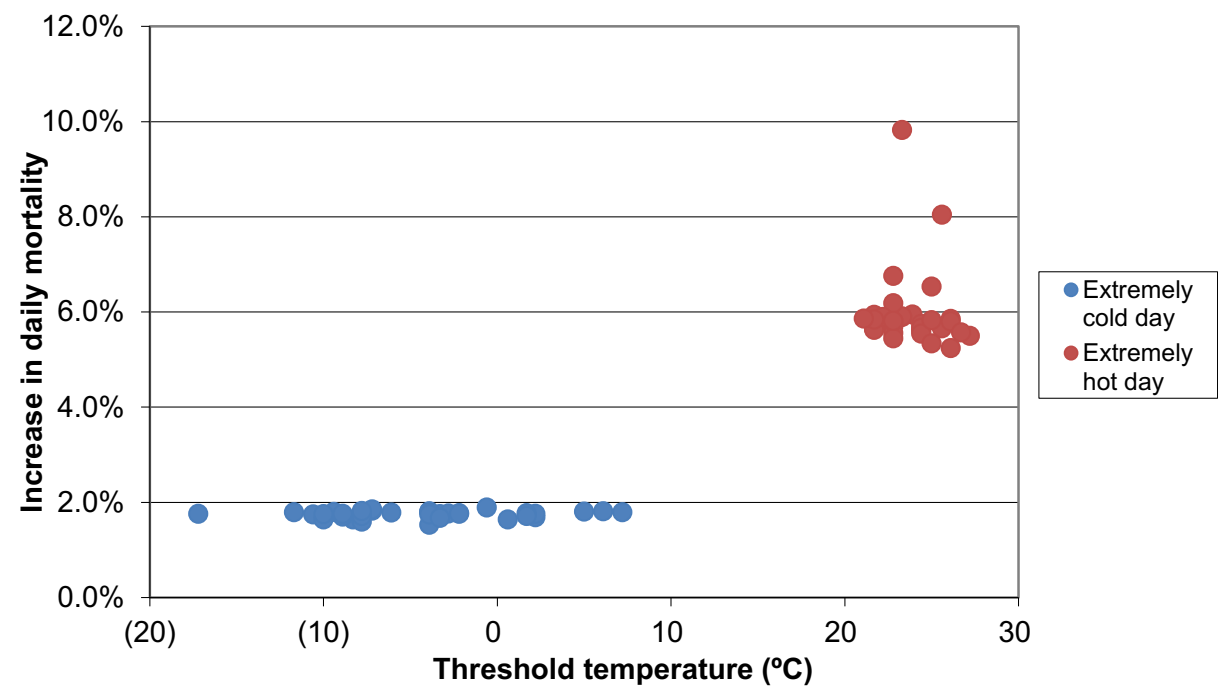

Fig. 1 Comparison of threshold temperatures and daily mortality response to extremely hot and cold days in the study cities 
global climate projections, are provided elsewhere in this special issue (Paltsev et al. 2013. Waldhoff et al. 2013, both this issue). In short, two emission scenarios were developed using the Massachusetts Institute of Technology Integrated Global System Model (IGSM): a reference (REF) scenario with unconstrained emissions with total radiative forcing of $10 \mathrm{~W} / \mathrm{m}^{2}$ by 2100 , and a stabilization scenario with a total radiative forcing of $3.7 \mathrm{~W} / \mathrm{m}^{2}$ by 2100 (POL3.7). In addition, all climate simulations used in this analysis assume a climate sensitivity of $3{ }^{\circ} \mathrm{C} .{ }^{2}$

Using these scenarios, future climate projections for the U.S. were developed. The IGSM Community Atmospheric Model (CAM) framework (Monier et al. 2013) links the IGSM to the National Center for Atmospheric Research CAM version 3. Because CAM is a threedimensional atmosphere model, the IGSM-CAM simulates not only changes in mean climate, but also simulates daily, annual, and decadal.

\subsection{Climate conditions over time and projections of extremely hot and cold days}

To evaluate the impact of climate change over time, we developed results centered on the following years: 2000, 2050, and 2100. Generally, we applied temperature anomalies derived from IGSM-CAM to a baseline period of observed daily minimum and maximum temperatures for weather station data for each city using the SimCLIM program (Warrick 2009; CLIMsystems 2010). Data from weather stations originally used in Medina-Ramon and Schwartz (2007) were incorporated where possible. Otherwise, we relied on data from the closest station with a complete baseline record (defined below).

Specifically, we created data for daily temperatures in each city in steps. First, for each city, we averaged the daily minimum and, separately, the daily maximum temperature for each day in the period from 1980 to 2009 to create a calendar year of baseline temperature values. This was done using the SIMCLIM weather station data, and separately, the IGSM-CAM data for the REF emissions scenario, for the grid cell with the weather station. IGSM-CAM anomalies were then calculated for the REF and POL3.7 emissions scenario by subtracting the averaged IGSM-CAM baseline for a selected day from the temperature projection for that day in a future year. This day-specific temperature anomaly was then added to the observed baseline to create the projected day's value for the temperature measure in a given year for a specific emissions scenario.

This process produces projected daily minimum and maximum temperatures calibrated with the Medina-Ramon and Schwartz (2007) temperature measures. IGSM-CAM was developed, in part, to help simulate natural variability and expected changes in future climate variability to help better simulate potential future changes in extreme events. Because IGSMCAM projections have significant interannual variability, this study examines three consecutive model years for each period analyzed: 1999-2001, 2049-2051, and 2099-2101. The average projected number of extremely hot and cold days for each year in a series was then used as the input to Eq. 1.

\subsection{City populations and projected population changes}

BenMAP was used to estimate 2010 populations in the 33 cities evaluated in this study. According to these data, the cities account for approximately 101 million of the 309 million U.S. residents.

\footnotetext{
${ }^{2}$ As described in Paltsev et al. (2013, this issue), the global temperature increases under the POL3.7 and REF (climate sensitivity of $3{ }^{\circ} \mathrm{C}$ ) by $1^{\circ}$ and $6{ }^{\circ} \mathrm{C}$, respectively, by 2100 from present day.
} 
To account for projected population changes, city-specific population adjustment factors were developed using all-age county-level population projections for 2010, 2050, and 2100 generated by the Integrated Climate and Land Use Scenarios (ICLUS) model (Bierwagen et al. 2010). ${ }^{3}$ The population adjustment factors for 2050 and 2100 are the ratio of the population in the cities in each year divided by the equivalent 2010 population. We multiply each city's 2010 result by its corresponding population adjustment factor to produce the 2050 and 2010 results that account for both climate and population changes.

\section{Results}

\subsection{Extreme temperature mortality under present climate}

Figure 1 shows Medina-Ramon and Schwartz (2007) found an extremely hot day generally increases daily mortality by roughly three times as much as an extremely cold day ( $\sim 6$ and $\sim 2 \%$, respectively).

Online Resource 2 presents the projected number of extremely cold and hot days for 19992001 and the corresponding average number of each type of day for the studied cities. Online Resource 3 presents the calculated number of deaths from extremely cold and extremely hot days in each city for the 2000 reporting year using the average number of each type of extreme temperature day (see Section 2.3 for the calculation description). Note that the results of this analysis do not reflect the directly observed meteorological data in each city, but rather the average of IGSM-CAM's projected data for the years 1999-2001. These values provide the baseline we use to calculate future changes in mortality from each type of extreme weather day under different emissions scenarios.

\subsection{Extreme temperature mortality under future climates}

Table 1 presents a summary of the number of extremely hot and cold days in the three time periods for the two emissions scenarios (REF and POL3.7) across the studied cities.

The REF scenario results in Table 1 reflect anticipated warming over the 21 st century in the absence of GHG emissions controls. In contrast, under the POL3.7 scenario, the increase in extremely hot days by 2050 is approximately $75 \%$ less than the REF case as a result of the emissions controls. Further, there is little increase in the number of extremely hot days from 2050 to 2100 under the POL3.7 scenario. In contrast, the average number of extremely hot days more than triples over this 50-year period in the REF scenario. For extremely cold days, the warming under both the Policy 3.7 and REF scenarios dramatically reduces the number of cities with identifiable extremely cold days by 2050 (nine cities for the POL3.7 scenario and five for the REF scenario). By 2100, in the REF scenario, only one city has a projected extremely cold day, while in the POL3.7 scenario, eight cities are still projected with extremely cold days. This is consistent with the observed warming stabilization described above for the extremely hot days.

Online Resources 4 and 5 provide detail on the projected number of extremely hot days by city for each emission scenario and each of the 3 years in the 2050 and 2100 reporting period

\footnotetext{
${ }^{3}$ The two emissions scenarios contain the same total population and population distribution for the U.S. Except for the national-scale population data from the Emissions Prediction and Policy Analysis (EPPA) model (Paltsev et al. 2013), all other ICLUS modeling parameters were set to the default values for the embedded ICLUS-A2 scenario.
} 
Table 1 Summary of extremely hot and cold days by period and emissions scenario across all studied cities

\begin{tabular}{|c|c|c|c|c|c|c|}
\hline Projected year & Average & Minimum & Maximum & Average & Minimum & Maximum \\
\hline & \multicolumn{3}{|c|}{$\begin{array}{l}\text { Extremely cold days under REF emissions } \\
\text { scenario }\end{array}$} & \multicolumn{3}{|c|}{$\begin{array}{l}\text { Extremely cold days under POL } 3.7 \\
\text { emissions scenario }\end{array}$} \\
\hline 1999-2001 average $^{\mathrm{a}}$ & 2.0 & 0.0 & 7.7 & 2.0 & 0.0 & 7.7 \\
\hline 2049-2051 average & 0.1 & 0.0 & 1.3 & 0.4 & 0.0 & 3.3 \\
\hline \multirow[t]{2}{*}{ 2099-2101 average } & 0.0 & 0.0 & 0.3 & 0.3 & 0.0 & 3.0 \\
\hline & \multicolumn{3}{|c|}{$\begin{array}{l}\text { Extremely hot days under REF emissions } \\
\text { scenario }\end{array}$} & \multicolumn{3}{|c|}{$\begin{array}{l}\text { Extremely hot days under POL } 3.7 \text { emissions } \\
\text { scenario }\end{array}$} \\
\hline 1999-2001 average $^{\mathrm{a}}$ & 4.9 & 0.0 & 28.0 & 4.9 & 0.0 & 28.0 \\
\hline 2049-2051 average & 21.4 & 1.0 & 53.0 & 9.1 & 0.0 & 35.0 \\
\hline 2099-2101 average & 65.6 & 21.0 & 102.3 & 9.2 & 0.3 & 33.3 \\
\hline
\end{tabular}

${ }^{\text {a }}$ REF and POL3.7 results are the same for years 1999-2001 as the envisioned emissions controls have not yet been implemented

and the associated 3-year average. In particular, these results highlight IGSM-CAM's interannual variability.

Table 2 presents the mortality results across the cities for the projected changes in extreme temperature days. The top of Table 2 presents projected changes in mortality from extreme temperature days compared to the year 2000 baseline across all cities for the REF and POL3.7 emissions scenarios holding the population at 2010 levels. The bottom of Table 2 provides these results after applying the ICLUS-based, city-specific population adjustment factors described in Section 2.4.

Table 2 Change in mortality projections compared to estimates for the baseline year

\begin{tabular}{|c|c|c|c|}
\hline \multirow{2}{*}{$\begin{array}{l}\text { Type of extreme temperature day and } \\
\text { emissions scenario }\end{array}$} & \multicolumn{3}{|c|}{ Projected change in mortality due to change in climate } \\
\hline & 2050 & 2100 & $\begin{array}{l}2100-\text { sensitivity with adjusted threshold }^{\text {a }} \\
\text { temperatures }^{\text {a }}\end{array}$ \\
\hline \multicolumn{4}{|l|}{ Estimates using 2010 population } \\
\hline Hot: POL3.7 & 561 & 496 & $(322)$ \\
\hline Hot: REF & 2,002 & 7,622 & 2,803 \\
\hline Cold: POL3.7 & $(65)$ & $(62)$ & 1,655 \\
\hline Cold: REF & $(68)$ & $(71)$ & 393 \\
\hline Hot and cold: POL 3.7 & 495 & 433 & 1,333 \\
\hline Hot and cold: REF & 1,934 & 7,551 & 3,196 \\
\hline \multicolumn{4}{|c|}{ Estimates adjusting population to projected year with ICLUS-based population growth factors } \\
\hline Hot: POL3.7 & 798 & 772 & $(383)$ \\
\hline Hot: REF & 2,818 & 12,592 & 5,407 \\
\hline Cold: POL3.7 & $(103)$ & $(111)$ & 2,271 \\
\hline Cold: REF & $(109)$ & $(132)$ & 508 \\
\hline Hot and cold: POL3.7 & 695 & 661 & 1,888 \\
\hline Hot and cold: REF & 2,709 & 12,461 & 5,915 \\
\hline
\end{tabular}

${ }^{\text {a }}$ Results based on all cities incorporating the warmest original threshold temperature value for both extremely hot and cold days 
Table 2 highlights the following results:

- Increases in projected deaths from extremely hot days

- Decreases in projected deaths from extremely cold days

- Increases in combined projected deaths from extremely hot and cold days within a year and scenario.

The last of these results, with the population held constant at 2010 levels (top half of Table 2), explicitly addresses the question of the net mortality impact of climate change on future extreme temperature days. The reduction in projected deaths from extremely cold days is more than offset by the projected increase in deaths from extremely hot days. This result holds for all reported future years for the POL3.7 and REF scenarios As a result, climate change clearly reflects an increasing health risk from extreme temperatures. Incorporating anticipated population changes (bottom half of Table 2) only reinforces this conclusion, as increasingly large populations would be exposed to the projected extreme temperatures.

\subsection{Benefits of a climate mitigation policy}

Table 3 presents estimates of the benefits of implementing GHG emissions controls. These results are calculated subtracting the POL3.7 results from the REF results from Table 2 in the different combinations of extreme temperatures and reporting years.

Table 3 consistently shows implementing emissions controls would reduce the future risk of deaths from extremely hot days (i.e., mortality values greater than zero). The indication of a disbenefit with respect to future mortality from extremely cold days reflects the reduced warming associated with the POL3.7 scenario. However, this small disbenefit is overwhelmed by the reduced mortality from extremely hot future days. The net benefit associated with the POL3.7 implementation increases over time and when projected population changes are accounted for.

Figure 2 provides an alternative summary of the benefits of implementing the POL3.7 scenario by representing how the mortality rate from projected extremely hot and cold days combined changes over time. In this figure, the increased mortality associated with the REF

Table 3 Mortality benefits of implementing the GHG emissions controls

\begin{tabular}{|c|c|c|}
\hline \multirow{2}{*}{$\begin{array}{l}\text { Type of extreme temperature day and emissions } \\
\text { scenario evaluation for benefits }\end{array}$} & \multicolumn{2}{|c|}{ Reporting year benefits are calculated for } \\
\hline & $2050 \quad 2100$ & $\begin{array}{l}2100-\text { sensitivity with adjusted } \\
\text { threshold temperatures }^{\text {a }}\end{array}$ \\
\hline \multicolumn{3}{|l|}{ Estimates using 2010 population } \\
\hline Hot: REF-policy 3.7 & 1,441 & 3,124 \\
\hline Cold: REF-policy 3.7 & (3) & $(1,261)$ \\
\hline Hot and cold: REF-policy 3.7 & $1,438 \quad 7,117$ & 1,863 \\
\hline \multicolumn{3}{|c|}{ Estimates adjusting population to projected year with ICLUS-based population growth factors } \\
\hline Hot: REF-policy 3.7 & $2,020 \quad 11,820$ & 5,791 \\
\hline Cold: REF-policy 3.7 & $(21)$ & $(1,764)$ \\
\hline Hot and cold: REF-policy 3.7 & $2,014 \quad 11,799$ & 4,027 \\
\hline
\end{tabular}

${ }^{\text {a }}$ Results based on all cities incorporating the warmest original threshold temperature value for both extremely hot and cold days 
scenario is clearly seen with the increase in size in the representative mortality circles over time. In contrast, the combined mortality rates with the POL3.7 scenario in future years do not show this dramatic increase. Figure 2 shows that most of the dramatic increases in mortality rates from the baseline to the 2050 period within the REF scenario occur in the Central U.S. By 2100 however, in the REF scenario, the southern and East Coast cities will also experience large increases in mortality rates relative to the year 2000 baseline.

The results in the first two columns of Tables 2 and 3 explicitly exclude consideration of the possibility of there being an adaptive response over time to extreme temperatures. To reflect potential adaptation over time we also evaluated the impacts of the changing climate over time by adjusting the threshold temperatures in the emissions scenarios as follows:

- Extreme heat days: the threshold temperature value in each city was increased to the highest daily minimum temperature value in the original group of 33 cities $\left(27.2^{\circ} \mathrm{C}\right.$ in Dallas-equivalent to $81.0^{\circ} \mathrm{F}$ )
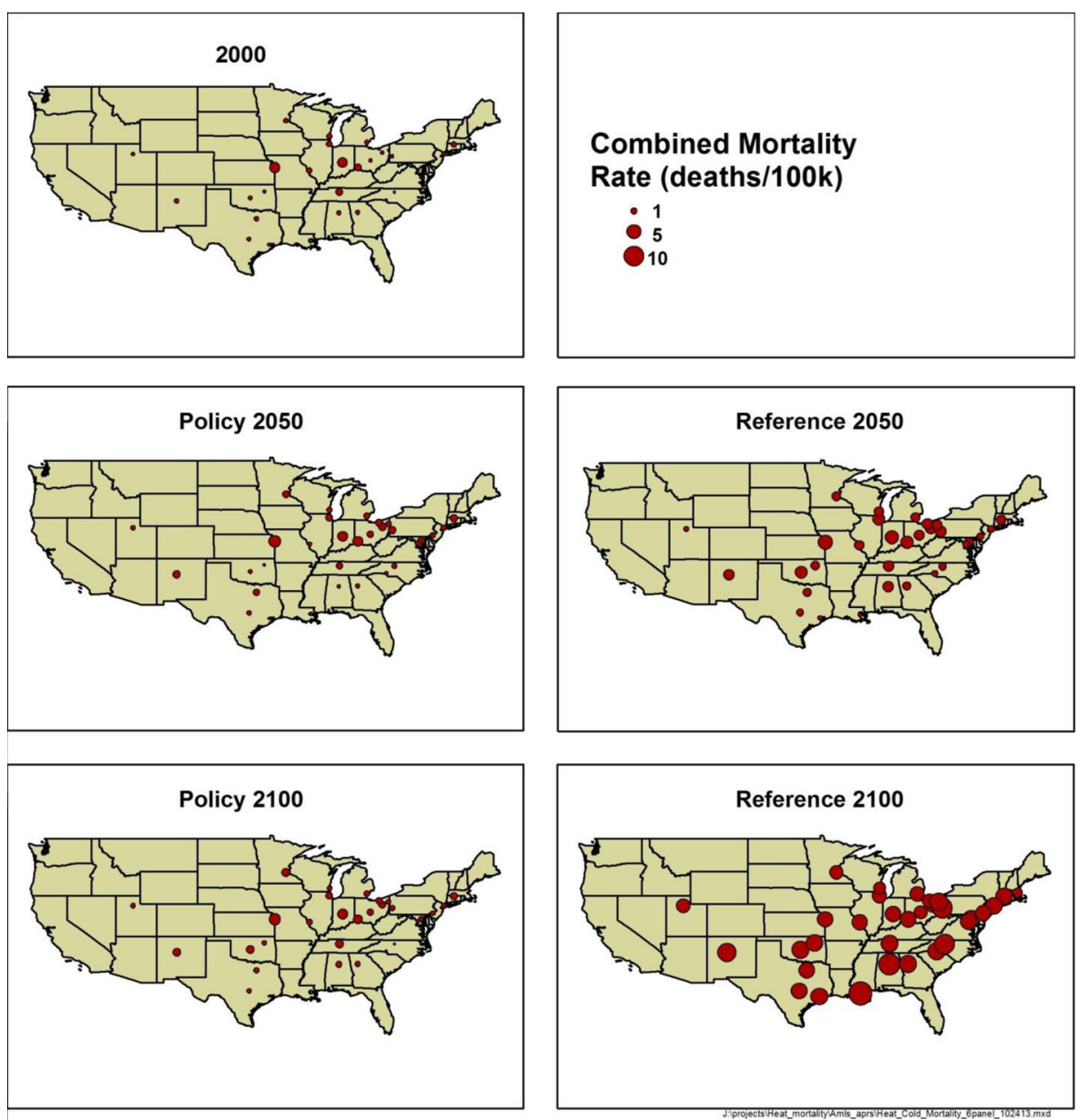

Fig. 2 Mortality rate from projected deaths from extremely hot and cold days per 100,000 city residents 
- Extreme cold days: the threshold temperature value in each city was increased to the highest daily maximum temperature value in the original group of 33 cities $\left(7.2^{\circ} \mathrm{C}\right.$ from New Orleans-equivalent to $45.0^{\circ} \mathrm{F}$ )

These adjustments, which do not include any change in the original city-specific mortality impact factors, reflect a hybrid of prior adaptation approaches of assuming a uniform, but equivalent increase in threshold temperatures (e.g., Gosling et al. 2009) and the use of an analogue city approach (see Kalkstein and Greene 1997; Knowlton et al. 2007). This adjustment is also consistent with research that has argued that even with climate change there will still be wintertime mortality from extremely relatively cold days (e.g., Kinney et al. 2012), This is consistent with a view that it is the relative shock of these days that is most important, not the absolute temperature. Further, this assumption was applied only to the projected climate data for the 3-year period centered around 2100 as this is when the impact of these adjustments is greatest.

The results of this analysis, presented in the third column of Tables 2 and 3, follow initial expectations. Specifically, with the warmer threshold temperatures the number of deaths from extremely cold days increases as more days in each location satisfy the new criterion. At the same time, the number of deaths attributable to extremely hot days declines as fewer days in the cities satisfy the revised criterion. However, the net result is that, while smaller than the original results, implementing POL3.7 still provides a net benefit considering the combined effects for both types of days. This result further supports the conclusion that warming as a result of projected climate changes will lead to a net increase in mortality risks/mortality.

\section{Discussion}

This analysis shows that unmitigated climate change (the REF scenario) produces increasingly greater mortality over time based on impacts from extreme temperatures quantified for 33 cities over the 21 st century. The results also highlight the potentially significant and increasing public health benefits that could accrue from implementing a GHG emissions control-based climate change mitigation policy. In considering these results, it is important to remember that the values reported for 2050 and 2100 reflect projections for individual years and the subset of the national population living in these cities. In other words, the total benefits over the whole country over time from implementing GHG emissions controls such as those in the POL3.7 scenario would likely be much larger.

There are two reasons why the results demonstrate that the potential reductions in deaths from changes in extremely cold days are likely to be overwhelmed by increases in deaths from extremely hot days. The first is presented in Fig. 1, where the percent increase in daily mortality from an extremely hot day is much larger in every studied city than the equivalent increase from an extremely cold day. As a result, even if climate change were to result in a decrease in the number of extremely cold days equal to the increase in the number of extremely hot days, there would still be a net mortality increase. The second reason is that, at least in these 33 cities, the potential increase in extremely hot days with climate change far exceeds the potential reduction in extremely cold days, as the latter is bounded by zero. This study specifically addresses mortality associated with extremely hot and cold days. By isolating the effect of single days of extreme cold temperatures the study results should not be affected by confounding factors related to generally higher wintertime mortality rates such as increased respiratory infections and cardiovascular disease (Medina-Ramon and Schwartz 2007; Mercer 2003). Several recent literature reviews suggest that the factors leading to these higher 
wintertime mortality rates are unlikely to be sensitive to climate warming (Ebi and Mills 2013; Kinney et al. 2012), and therefore the changes in cold mortality identified by this study are likely to compose the majority of the changes in winter-time deaths resulting from warming.

Our results also provide for a measure of comparison with other estimates of the health impacts of extreme weather. For example, we estimate roughly 550 deaths from extremely hot days in the baseline period for the 33 cities (Online Resource 3) compared to the 1,540 average summertime extreme heat event deaths estimated in 40 cities in the synoptic approach of Greene et al. (2011). While the population considered in Greene et al. was only 38 million compared to 101 million in this study, it is still difficult to make definitive statements about the differences between the results because of the difference between the synoptic and temperature threshold methodologies. Greene et al. (2011) also calculated mortality from extreme heat in future years and found an increase of roughly 1,800 deaths by 2050 and roughly 4,200 additional deaths by 2100 . These estimates can also be compared to an increase in all-cause or non-accidental heat-related national mortality by 2050 from Voorhees et al. (2011) of roughly 5,000 deaths, using a similar relative risk function approach but at a national rather than city-specific scale; sensitivity analyses using response results from other studies expanded this range to up to 27,000 deaths.

The general sign and magnitude of these results remained largely the same in our sensitivity analysis which incorporated a strong adaptation assumption. Specifically, as we incorporated the warmest observed temperature thresholds for calculating extreme cold and extremely hot days, we continued to find the projected mortality increases from extremely hot days overwhelming potential reductions in the number of deaths attributable to extremely cold days.

However, our methods and results still carry a number of important caveats.

First, the current study design is based solely on changes in the number of extreme temperature days during the summer (May to September) and winter (November to March) seasons. Therefore, the current mortality response functions are incapable of accounting for the extent to which a threshold temperature is exceeded, or for days that exceed the heat threshold outside the defined seasons of interest. While Medina-Ramon and Schwartz (2007) generally account for this in producing average response values based on multiple years of data, this becomes more of an issue in the current application where past temperature distributions may be less reflective of anticipated future conditions. In particular, there are questions about how populations may respond to increasing numbers of days with temperatures that are beyond their current experience. In addition, other studies have shown that mortality can be sensitive to timing. Using a Bayesian approach, some studies have determined that for extreme heat events, the length and intensity of the event increased mortality risk, and that mortality risk was higher during the first heat wave of the season (e.g., Anderson and Bell 2011). Meanwhile, Zanobetti et al. (2012) found that the elderly may be more vulnerable to summertime temperature variability than absolute temperature.

Second, our mortality impact factors are currently based on results from an epidemiological study that did not differentiate the mortality impact of these extreme temperature days based on the age of the deceased. Because older individuals have long been recognized as being at elevated risk during extreme temperature events, the lack of age-based mortality impact factors may result in an undercount of potential future impacts given the anticipated rapid growth of the older segments of the U.S. population in the 21 st century.

Third, while this study provides a first step for investigating the potential impact of adaptation on future mortality by providing results both for a no-adaptation and an analogue city approach, it would be difficult to more precisely estimate the effect, nature, and cost of these adaptations. Natural acclimatization (Kinney et al. 2008) and autonomous changes in behavior and infrastructure (Sheridan et al. 2012 and Davis 
et al. 2002) can take place without central planning. Planned adaptation may also play a role: considerable effort has already been committed at both local and federal levels to developing and implementing extreme temperature response programs, especially for extreme heat (U.S. EPA 2006; CDC 2009, 2011).

Fourth, our results do not account for the potential impact or extent of any mortality displacement (i.e., "harvesting"). The underlying Medina-Ramon and Schwartz (2007) study found no evidence of harvesting from extreme temperatures, in contrast to less extreme but still elevated temperatures, at a lag time of 1 day, but did not assess harvesting at longer lag times (see discussion on page 831-832 in their study). However recognizing the importance of this topic, Online Resource 6 provides additional discussion of harvesting in general and the potential for and potential magnitude of the impact of harvesting in our results, surveying studies which found harvesting effects between 10 and $72 \%$ depending on the mortality event.

It must also be recognized that our results come from one scenario and one model using results from a limited set of years, applying mortality estimates from a single paper. Other climate models, and potentially different specifications of these scenarios within the IGSMCAM model, could project different distributions of future extreme temperature days and thus would generate results that would be different in their specific details if perhaps not in their general conclusions. ${ }^{4}$

\section{Conclusions}

Continued warming over this century is anticipated to increase deaths from extremely hot and cold days combined. This result holds across the scenarios we evaluated and the analog city-based sensitivity analysis. As a result, we find that a policy to reduce future GHG emissions could reduce the increase in the combined mortality from these extreme temperature days.

These results provide an important example of how climate change may affect human health. Similar quantitative results for a baseline and policy implementation scenario could potentially be developed for other climate-sensitive health stressors, such as particulate air pollution and ozone, where epidemiological studies can define how the incidence of a specific health outcome is expected to change in a population in response to changing exposures. However, while a wide range of health stressors (e.g., waterborne pathogens, aeroallergens) and disease categories (e.g., vectorborne) are found to be sensitive to climate change (Ebi et al. 2008), there are limited quantitative estimates of the magnitude of such outcomes. As research addresses these gaps, a clearer picture of the potential overall health impacts of climate change and climate mitigation policies is likely to emerge.

Acknowledgments The authors would like to thank Jeremy Hess of Emory University and Shubhayu Saha of the Centers for Disease Control and Prevention as well as colleagues at Stratus Consulting and U.S. Environmental Protection Agency's (EPA's) Climate Change Division who provided comments on earlier versions of the paper. However, the views expressed in this document are solely those of the authors and do not necessarily reflect those of EPA.

\footnotetext{
${ }^{4}$ Monier et al. (2013) provides additional information of the regarding the sensitivity of the IGSM-CAM model results to initilializing conditions, specifically Online Resource 2.
} 
Open Access This article is distributed under the terms of the Creative Commons Attribution License which permits any use, distribution, and reproduction in any medium, provided the original author(s) and the source are credited.

\section{References}

Anderson BG, Bell ML (2009) Weather-related mortality: how heat, cold and heat waves affect mortality in the United States. Epidemiol 20(2):205-213

Anderson BG, Bell ML (2011) Heat waves in the United States: mortality risk during heat waves and effect modification by heat wave characteristics in 43 US communities. Environ Health Perspect 119(2):210-218

Basu R, Samet JM (2002) Relation between elevated ambient temperature and mortality: a review of the epidemiologic evidence. Epidemiol Rev 24(2):190-202

Bierwagen BG, Theobald DM, Pyke CR, Choate A, Groth P, Thomas JV, Morefield P (2010) National housing and impervious surface scenarios for integrated climate impact assessments. Proc Natl Acad Sci 107(49): 20887-20892

CDC (Centers for Disease Control and Prevention) (2009) Extreme heat: a prevention guide to promote your personal health and safety. http://emergency.cdc.gov/disasters/extremeheat/heat guide.asp. Accessed 3 Feb 2011

CDC (Centers for Disease Control and Prevention) (2011) Climate and health program. http://www.cdc.gov/ climatechange/. Accessed 9 Mar 2011

CLIMsystems (2010) SimCLIM software. CLIMsystems, Ltd., Hamilton

Davis RE, Knappenberger PC, Novicoff WM, Michaels PJ (2002) Decadal changes in heat-related human mortality in the Eastern US. Clim Res 22:175-184

Ebi KL, Mills D (2013) Winter mortality in a warming climate: a reassessment. WIREs Clim Chang 4 (3):203-212

Ebi KL, Balbus J, Kinney PL, Lipp E, Mills D, O’Neill MS, Wilson M (2008) Effects of global change on human health. In: Gamble JL, Ebi KL, Sussman FG, Wilbanks TJ (eds) Analyses of the effects of global change on human health and welfare and human systems. A report by the U.S. Climate Change Science Program and the Subcommittee on Global Change Research. U.S. Environmental Protection Agency, Washington, pp 2-1-2-78

Gosling SN, Lowe JA, McGregor GR (2009) Climate change and heat-related mortality in six cities part 2: climate model evaluation, sensitivity analysis, and estimation of future impacts. Int J Biometeorol 53:31-51

Greene S, Kalkstein LS, Mills DM, Samenow J (2011) An examination of climate change on extreme heat events and climate-mortality relationships in large U.S. cities. Weather Clim Soc 3(4):281-292

Huang C, Barnett AG, Wang X, Vaneckova P, Fitzgerald G, Tong S (2011) Projecting future heat-related mortality under climate change scenarios: a systematic review. Environ Health Perspect 119(12):1681-1690

IPCC (Intergovernmental Panel on Climate Change) (2011) Summary for policymakers. In: Field CB, Barros V, Stocker TF, Qin D, Dokken D, Ebi KL, Mastrandrea MD, Mach KJ, Plattner G-K, Allen SK, Tignor M, Midgley PM (eds) Intergovernmental panel on climate change special report on managing the risks of extreme events and disasters to advance climate change adaptation. Cambridge University Press, Cambridge, United Kingdom and New York, NY, USA

Kalkstein LS, Greene JS (1997) An evaluation of climate/mortality relationships in large U.S. cities and the possible impacts of climate change. Environ Health Perspect 105:84-93

Karl TR, Melillo JM, Peterson TC (eds) (2009) Global climate change impacts in the United States. Cambridge University Press, New York

Kinney PL, O’Neill MS, Bell ML, Schwartz J (2008) Approaches for estimating effects of climate change on heat-related deaths: challenges and opportunities. Environ Sci Pol 11:87-96

Kinney PL, Pascal M, Vautard R, Laaid K (2012) Winter mortality in a changing climate: will it go down. Bull Epidemiol Hebd 12-13:148-151

Knowlton K, Lynn B, Goldberg RA, Rosenzweig C, Hogrefe C, Rosenthal JK, Kinney PL (2007) Projecting heat-related mortality impacts under a changing climate in the New York City region. Am J Public Health 97 (11):2028-2034

McGeehin MA, Mirabelli M (2001) The potential impacts of climate variability and change on temperature-related morbidity and mortality in the United States. Environ Health Perspect 109 (Supplement 2):185-189

Medina-Ramon M, Schwartz J (2007) Temperature, temperature extremes, and mortality: a study of acclimatization and effect modification in 50 US cities. Occup Environ Med 64:827-833

Meehl GA, Tebaldi C, Walton G, Easterling D, McDaniel L (2009) Relative increase of record high maximum temperatures compared to record low minimum temperatures in the U.S. Geophys Res Lett 36, L23701 
Mercer JB (2003) Cold-an underrated risk factor for health. Environ Res 92:8-13

Monier E, Gao X, Scott J, Sokolov A, Schlosser A (2013) A framework for modeling uncertainty in regional climate change. Clim Chang (submitted, this issue)

Paltsev S, Monier E, Scott J, Sokolov A, Reilly J (2013) Integrated economic and climate projections for impact assessment. Clim Chang (submitted, this issue)

Sheridan SC, Allen MJ, Lee CC, Kalkstein LS (2012) Future heat vulnerability in California, part II: projecting future heat-related mortality. Clim Chang. doi:10.1007/s10584-012-0437-1

U.S. EPA (U.S. Environmental Protection Agency) (2006) Excessive heat events guidebook. EPA 430-B-06-005. U.S. Environmental Protection Agency, Washington

U.S. EPA (U.S. Environmental Protection Agency) (2012) Environmental Benefits Mapping and Analysis Program (BenMAP). http://www.epa.gov/air/benmap/. Accessed 13 Apr 2012

Voorhees AS, Fann N, Fulcher C, Dolwick P, Hubbell B, Bierwagen B, Morefield P (2011) Climate changerelated temperature impacts on warm season heat mortality: a proof-of-concept methodology using BenMAP. Environ Sci Technol 45:1450-1457

Waldhoff S, Martinich J, Sarofim M, DeAngelo B, McFarland J, Jantarasami L, Shouse K, Crimmins A, Li J (2013) Overview of the special issue: a multi-model framework to achieve consistent evaluation of climate change impacts in the United States. Clim Chang (submitted, this issue)

Warrick R (2009) The evolution of the SimCLIM modeling environment: from CLIMPACTS to SimCLIM: development of an integrated assessment model system. In: Knight CG, Jäger J (eds) Integrated regional assessment of global climate change. Cambridge University Press, Cambridge, pp 280-311

Zanobetti A, O'Neill MS, Grolund CJ, Schwartz JD (2012) Summer temperature variability and long-term survival among elderly people with chronic disease. Proc Natl Acad Sci. doi:10.1073/pnas.113070109, Online 9 April 2012 